\title{
Effects of alternative label formats on choice of high- and low-sodium products in a New Zealand population sample
}

\author{
Rachael McLean ${ }^{1, *}$, Janet Hoek ${ }^{2}$ and Duncan Hedderley ${ }^{3}$ \\ ${ }^{1}$ Edgar National Centre for Diabetes \& Obesity Research, Dunedin School of Medicine, University of Otago, \\ PO Box 913, Dunedin 9054, New Zealand: '2Department Marketing, University of Otago, Dunedin, \\ New Zealand: ${ }^{3}$ The New Zealand Institute for Plant and Food Research Ltd, Palmerston North, New Zealand
}

Submitted 26 July 2011: Accepted 7 December 2011: First published online 27 January 2012

\begin{abstract}
Objective: Dietary sodium reduction is a cost-effective public health intervention to reduce chronic disease. In response to calls for further research into front-of-pack labelling systems, we examined how alternative sodium nutrition label formats and nutrition claims influenced consumers' choice behaviour and whether consumers with or without a diagnosis of hypertension differed in their choice patterns.

Design: An anonymous online experiment in which participants viewed ten choice sets featuring three fictitious brands of baked beans with varied label formats and nutritional profiles (high and low sodium) and indicated which brand in each set they would purchase if shopping for this product.

Setting: Participants were recruited from New Zealand's largest online nationwide research panel.

Subjects: Five hundred people with self-reported hypertension and 191 people without hypertension aged 18 to 79 years.

Results: The addition of a front-of-pack label increased both groups' ability to discriminate between products with high and low sodium, while the Traffic Light label enabled better identification of the high-sodium product. Both front-of-pack formats enhanced discrimination in the presence of a reduced salt claim, but the Traffic Light label also performed better than the Percentage Daily Intake label in moderating the effect of the claim for the high-sodium product.

Conclusions: Front-of-pack labels, particularly those with simple visual cues, enhance consumers' ability to discriminate between high- and low-sodium products, even when those products feature nutrition claims.
\end{abstract}

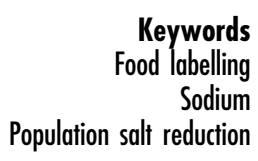

Keywords

Sodium

Population salt reduction
Sodium, mostly in the form of sodium chloride or salt, is used to enhance flavour, preserve and improve processing in a wide range of foods. However, dietary salt consumption in many countries, including New Zealand, significantly exceeds the WHO recommended maximum intake of $5 \mathrm{~g} / \mathrm{d}$ for adults ${ }^{(1)}$. Current estimates suggest that the mean salt intake for New Zealanders is about $9 \mathrm{~g} / \mathrm{d}$ (CD Thomson and AJ Colls, unpublished results), considerably more than the recommended upper limit for New Zealand adults of $6 \mathrm{~g} / \mathrm{d}$ (or $2300 \mathrm{mg} \mathrm{Na} / \mathrm{d}$ ) ${ }^{(2)}$. The adverse health effects of excessive dietary sodium have been well documented. Observational and intervention studies have shown a consistent causal association between high sodium intake and elevated blood pressure $^{(3,4)}$, with consequent increased risk of CHD and stroke $^{(5)}$. A high salt intake is also associated with an increased risk of kidney disease, gastric cancer and osteoporosis $^{(6)}$. US estimates suggest moderating Americans' sodium intake by as little as $1200 \mathrm{mg} / \mathrm{d}$ could reduce annual deaths by 44000 and save between \$US 10 billion and \$US 24 billion in annual health-care costs ${ }^{(7)}$.
Processed foods account for about three-quarters of sodium intake in Western diets, with a further 10-15\% added in cooking and at the table ${ }^{(8-10)}$. Changing food composition, and thus consumers' food supply, would offer the greatest opportunity to reduce population sodium intake $e^{(6,8)}$. Reducing the amount of sodium in processed food has formed the cornerstone of salt reduction campaigns, and many food manufacturers have committed to sodium reduction programmes to this end ${ }^{(11)}$. However effective nutrition labelling has also been shown to be a cost-effective intervention to improve population nutrition $^{(12)}$. Labelling also enables consumers to have greater control over their nutrition in an environment that promotes unhealthy food choices.

The UK Food Standards Authority's salt reduction campaign launched in 2003 included the publication of sodium targets for a wide range of foods, and has resulted in a $10 \%$ reduction in population mean salt intake from $9.5 \mathrm{~g} / \mathrm{d}$ in $2000 / 01$ to $8.6 \mathrm{~g} / \mathrm{d}$ in 2008 . The campaign also included a public awareness campaign focusing on 
educating consumers about the adverse health effects of a high salt intake, supported by education about how to interpret food labels, enabling consumers to identify lowsalt options ${ }^{(11)}$. Successful interventions in Finland have also attempted to shape demand by making it easier for consumers to differentiate between products with high and low sodium concentrations ${ }^{(13)}$.

Regulators in many countries have used nutrition labels to provide information that could assist consumers to make healthier food choices. Recent attempts have sought to mandate labels that enhance consumer understanding and research has focused on identifying which label formats communicate information most effectively ${ }^{(14)}$. The Food and Drug Administration and the Institute of Medicine in the USA have recently called for further research to identify the best way to communicate nutritional information to consumers through food labelling ${ }^{(15)}$. The European Union recently decided to mandate nutrition labelling of pre-packed foods, but decided against requiring a Traffic Light (TL) label in favour of a Percentage Daily Intake (PDI) model after intense lobbying by the food industry ${ }^{(16)}$.

There is ongoing debate about whether to use the term 'sodium' or 'salt' on food labels. The USA and Canada widely use the term 'sodium' in a public health context; however public health campaigners in the UK and Australia have generally chosen to use 'salt' as a term that people are likely to be more familiar with and this is reflected in the use of 'salt' in nutrition claims. The European Union has also recently decided to use the word 'salt' in preference to 'sodium' in front-of-pack labels. In New Zealand and Australia there is some confusion among consumers about the relationship between sodium and salt in food labels ${ }^{(17,18)}$. Although the sodium and salt are not the same (1 $\mathrm{g}$ sodium $=\sim 2.5 \mathrm{~g}$ salt) we have used the terms interchangeably in the present paper as about $90 \%$ of sodium intake is from salt, and this approach reflects how the terms appear in existing label and claim formats.

We tested three labelling formats, illustrated in Fig. 1. The Nutrition Information Panel (NIP) has been mandatory in New Zealand since 2002, and is highly numeric. Several food manufacturers have voluntarily introduced front-of-pack PDI labels in New Zealand that they believe complement the mandatory $\mathrm{NIP}^{(19)}$ while the TL label was developed in 2007 by the Food Standards Agency in the UK to communicate fat, saturated fat, salt and sugar levels of food and is not currently in use in New Zealand. The TL label has no numeric information, but instead has low, medium and high nutrient categories, using the traffic light to convey the appropriate category grading in a highly visual way. Both front-of-pack labels (PDI and TL) have greater visual impact than the NIP, which is usually small and situated on the back or side of a food packet.

To explore alternative methods of communicating information about sodium content to consumers, we used a choice modelling study to compare how three different
1. Nutrition Information Panel (NIP)*

\begin{tabular}{|c|c|c|}
\hline \multicolumn{3}{|c|}{ NUTRITION INFORMATION } \\
\hline \multicolumn{3}{|l|}{ Servings per can: 2} \\
\hline \multicolumn{3}{|l|}{ Serving size: $210 \mathrm{~g}$} \\
\hline & $\begin{array}{r}\text { Average } \\
\text { Quantity } \\
\text { Per serving }\end{array}$ & $\begin{array}{l}\text { Average } \\
\text { Quantity } \\
\text { Per } 100 \mathrm{~g}\end{array}$ \\
\hline ENERGY & $895 \mathrm{~kJ}$ & $425 \mathrm{~kJ}$ \\
\hline PROTEIN & $10.8 \mathrm{~g}$ & $5.1 \mathrm{~g}$ \\
\hline FAT: TOTAL & $1.2 \mathrm{~g}$ & $0.6 \mathrm{~g}$ \\
\hline -SATURATED & $0.2 \mathrm{~g}$ & $0.1 \mathrm{~g}$ \\
\hline CARBOHYDRATE & $33.7 \mathrm{~g}$ & $16.1 \mathrm{~g}$ \\
\hline -SUGARS & $15.5 \mathrm{~g}$ & $7.4 \mathrm{~g}$ \\
\hline DIETARY FIBRE & $11.9 \mathrm{~g}$ & $5.7 \mathrm{~g}$ \\
\hline SODIUM & $252 \mathrm{mg}$ & $120 \mathrm{mg}$ \\
\hline POTASSIUM & $650 \mathrm{mg}$ & $310 \mathrm{mg}$ \\
\hline IRON & $2.7 \mathrm{mg}$ & $1.3 \mathrm{mg}$ \\
\hline
\end{tabular}

2. Percentage Daily Intake (PDI) label†

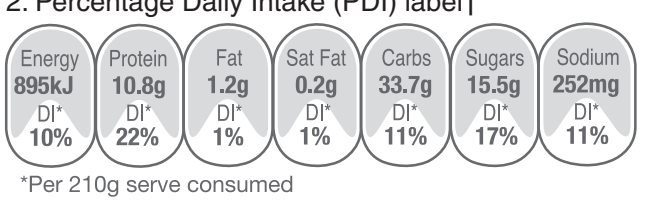

3. Traffic Light (TL) labelł

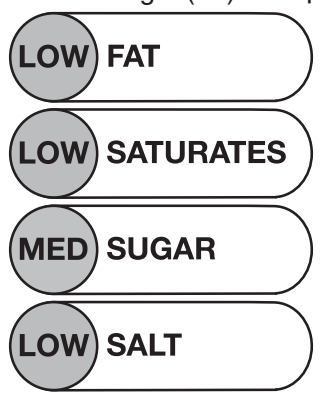

Fig. 1 Examples of the three labelling formats used. *The NIP is highly numeric, situated on back or side of the pack, and has been mandatory in New Zealand since 2002. †The PDI label was introduced voluntarily by several food manufacturers; it is a front-ofpack label with greater visual impact, although still highly numeric. $\$$ The TL label contains no numeric information; it is a front-of-pack label and has the highest visual impact, with green, amber and red colours representing low, medium and high levels, respectively. The TL label was developed by the UK Food Standards Agency in 2007 and is not currently in use in New Zealand

nutrition label formats and two nutrition claims influenced consumers' choice behaviour. Stated choice experiments simulate actual behaviour and enable the importance of attributes to be estimated rather than assumed. Given that consumers often overestimate their use of nutritional information $^{(20,21)}$, this methodology is particularly appropriate for estimating behaviours such as food purchasing, where self-reported behaviour may be affected by social desirability bias. We tested three key hypotheses:

1. Consumers' ability to discriminate between high- and low-sodium foods would increase as nutrition labels become less numeric and more visual.

2. Consumers with hypertension would have a greater awareness of the importance of sodium reduction for 
blood pressure control and so would demonstrate stronger discrimination between high- and low-sodium foods when these featured nutrition labels that were less numeric and more visual.

3. The persuasive effect of product nutrition claims would diminish as nutrition labels become less numeric and more visual.

\section{Experimental methods}

A random sample of participants was recruited from New Zealand's largest pre-existing national online research panel, which comprises over 125000 New Zealanders. The sample had been pre-screened to include individuals who reported that a doctor had diagnosed them with hypertension. The sample was randomly selected from the online panel and recruitment closed once the required sample (600 people with hypertension and 300 people without hypertension) had been achieved. Respondents were asked to identify whether they were 'mainly responsible', 'partly responsible' or 'not at all responsible' for their household grocery shopping. Only those who indicated that they were mainly or partly responsible were able to continue with the remainder of the survey. Participants viewed choice sets containing three fictitious baked bean brands that differed in their sodium content, nutrition label format and nutrition claim ('low salt' or 'reduced salt'). Levels of other nutrients did not differ between the high- and low-sodium products. The three label formats (illustrated in Fig. 1) included (i) an NIP situated on the back of the can, (ii) an NIP on the back and a PDI label on the front, and (iii) an NIP on the back and a TL label on the front.

Although each screen showed front-of-can images, participants could view the NIP by hovering their mouse over each image; this revealed a back-of-can image and simulated in-store behaviour, where consumers must make a conscious decision to view a product's NIP. The 'low salt' claim was not used on the cans with the highsodium nutrition profile, as this would have been illogical and contrary to current New Zealand regulations. These state that a product can be labelled 'low salt' if it contains less than $120 \mathrm{mg} \mathrm{Na} / 100 \mathrm{~g}$, and labelled 'reduced salt' if the food has at least $25 \%$ less sodium than the comparative reference food ${ }^{(22)}$. Respondents viewed ten showcards, each featuring three images that varied according to the brand, nutrition profile, nutrition label and nutrition claim (see Table 1). They reviewed the images as though they were in a supermarket considering buying baked beans, then selected the brand they would buy if they had only the options shown available to them. The presentation order was randomized and balanced using a Latin square design ${ }^{(23)}$. Finally, participants answered questions relating to their use of food labels and provided basic demographic and health information, including whether they had ever been told they had high blood pressure.
Table 1 Experimental design

\begin{tabular}{ll}
\hline Attribute & Number and levels tested \\
\hline Brand & 3: all fictitious to avoid prior behavioural effects \\
Front-of-pack & 3: none, PDI, TL \\
$\quad$ labels & 3: none, reduced salt, low salt+ \\
Product claim & 2: high or low sodium \\
\hline
\end{tabular}

PDI, Percentage Daily Intake; TL, Traffic Light.

tThe 'low salt' claim was not used with the high-sodium product since this would have created a logically inconsistent option, and would not be consistent with current New Zealand labelling regulations.

\section{Statistical methods}

Descriptive analyses and linear regression testing of associations between education and self-reported use of nutrition labels were performed using the STATA statistical software package version $11 \cdot 1$ (StataCorp LP, College Station, TX, USA). To examine the effects of different labelling formats including addition of a PDI or TL label and the presence or absence of a nutrition claim, we fitted a multinomial logit regression model that enabled the attributes' main and interaction effects to be estimated, following the method of Chen and Kuo ${ }^{(24)}$, using the software GenStat version 13 (2010; VSN International Ltd, Hemel Hempstead, UK).

\section{Results}

Nine hundred and seventy-four people responded to the survey; of these, 678 had been pre-screened as having reported a history of diagnosed hypertension and 296 were from the general sample. In order to ensure real differences between groups, we excluded those in the pre-screened people with hypertension who answered 'no' to the question 'Have you ever been told you have high blood pressure?', leaving 500 in the group of people with hypertension. We excluded those in the general population sample who answered 'yes' to the question 'Have you or someone you live with ever been told you have high blood pressure?', leaving 191 participants in the group without hypertension.

People with hypertension were significantly older than those without, but there was no significant difference between the two groups with respect to education (Table 2). People with hypertension were significantly more likely than people without hypertension to report being on a special diet (61\% v. 41\%, respectively) and were more likely to have been advised to reduce the salt in their diet $(58 \% v$. $20 \%$, respectively). People with hypertension were significantly more likely to report reading nutrition panels and were more likely to report reading the NIP on a new brand of food. However, there was no significant difference between the groups with respect to self-reported confidence in using the NIP to evaluate foods (Table 3).

Linear regression analysis showed a statistically significant relationship between level of education and 
Table 2 Demographic information of participants by hypertensive status: New Zealanders aged 18-79 years participating in an online nationwide research panel

\begin{tabular}{lccc}
\hline & $\begin{array}{c}\text { Participants without } \\
\text { diagnosed hypertension }\end{array}$ & $\begin{array}{c}\text { Participants with } \\
\text { hypertension }\end{array}$ & $P$ value \\
\hline Sample size & 191 & 500 & \\
Age (years) & $18-75$ & $19-79$ & \\
$\quad$ Range & 43 & 53 & $0 \cdot 0001 \ddagger$ \\
Mean & & & \\
Gender (\%) & 42 & 43 & \\
$\quad$ Male & 58 & 57 & $0 \cdot 975 \S$ \\
Female & & & $0 \cdot 079 \S$ \\
Ethnicity (\%)† & 80 & 80 & $0 \cdot 023 \S$ \\
NZ European & 6 & 10 & $0 \cdot 302 \ddagger$ \\
Māori & 20 & 13 & \\
Other & & 20 & \\
Education (\%) & 11 & 26 & 12 \\
$\quad$ No formal qualification & 33 & 20 & \\
School qualifications & 13 & 13 & \\
Trade qualifications & 10 & \\
Certificate or diploma & 18 & 10 & \\
Postgraduate qualification & 17 & & \\
\hline
\end{tabular}

†Participants were able to identify with more than one ethnic group, so adds to $>100 \%$. fUsing the $t$ test for difference between means. $U$ Using the $\chi^{2}$ test for difference in proportions.

Table 3 Self-reported label use of participants by hypertensive status: New Zealanders aged 18-79 years participating in an online nationwide research panel

\begin{tabular}{|c|c|c|c|}
\hline & $\begin{array}{l}\text { Participants without } \\
\text { diagnosed hypertension }\end{array}$ & $\begin{array}{l}\text { Participants with } \\
\text { hypertension }\end{array}$ & $P$ valuet \\
\hline $\begin{array}{l}\text { Sample size } \\
\text { I often read the nutrition information panels on packaged foods when } \\
\text { shopping ( } 1=\text { strongly disagree to } 9=\text { strongly agree) }\end{array}$ & 191 & 500 & \\
\hline $\begin{array}{l}\text { Mean } \\
\text { If I was thinking of buying a new brand, I would always read the nutrition } \\
\text { information panel before deciding whether to buy it ( } 1=\text { strongly } \\
\text { disagree to } 9=\text { strongly agree) }\end{array}$ & $5 \cdot 5$ & $6 \cdot 1$ & 0.003 \\
\hline $\begin{array}{l}\text { Mean } \\
\text { I feel confident that I can use nutrition information panels to work out } \\
\text { how healthy a food is }(1=\text { I do not feel confident at all to } 9=\text { I am highly } \\
\text { confident I can do this) }\end{array}$ & $5 \cdot 8$ & $6 \cdot 6$ & $<0.0001$ \\
\hline $\begin{array}{l}\text { Mean } \\
\text { Are you currently on a diet or paying special attention to what you eat? } \\
\text { (Yes/No) }\end{array}$ & $4 \cdot 9$ & $5 \cdot 1$ & $0 \cdot 4804$ \\
\hline $\begin{array}{l}\text { Yes }(\%) \\
\text { No }(\%)\end{array}$ & $\begin{array}{l}41 \\
59\end{array}$ & $\begin{array}{l}61 \\
39\end{array}$ & $<0 \cdot 0001$ \\
\hline $\begin{array}{l}\text { Is anyone else in your household on a diet or paying special attention to } \\
\text { what they eat? (Yes/No/Don't know) }\end{array}$ & & & \\
\hline $\begin{array}{l}\text { Yes }(\%) \\
\text { No (\%) } \\
\text { Don't know (\%) }\end{array}$ & $\begin{array}{r}35 \\
62 \\
3\end{array}$ & $\begin{array}{r}37 \\
60 \\
3\end{array}$ & $0 \cdot 766$ \\
\hline Have you ever been advised to reduce the salt in your diet? (Yes/No) & & & \\
\hline $\begin{array}{l}\text { Yes }(\%) \\
\text { No }(\%)\end{array}$ & $\begin{array}{l}20 \\
80\end{array}$ & $\begin{array}{l}58 \\
42\end{array}$ & $<0 \cdot 0001$ \\
\hline
\end{tabular}

tUsing the $t$ test for difference between means.

participants' self-reported reading of NIP. As participants' education level increased, they were more likely to report reading the NIP $(\beta=0 \cdot 26,95 \%$ CI $0 \cdot 14,0 \cdot 38, P<0 \cdot 001)$ but were less likely to report feeling confident about using the NIP $(\beta=-0 \cdot 16,95 \% \mathrm{CI}-0 \cdot 28,-0 \cdot 04, P=0 \cdot 009)$.

To test the first and second hypotheses, we examined whether the different label formats affected respondents' ability to differentiate between products with varying sodium content by hypertensive status. The multinomial logit model indicated that all three factors (label format, sodium level and nutrition claim) significantly affected choice, and there were significant interactions between these factors. However, most of these effects were the same for people with hypertension and those without hypertension. The only significant interaction between the groups and the factors was for the sodium level; while 
both groups favoured low-salt options, the preference was stronger in the group of people with hypertension (Wald statistic $=7 \cdot 6,1 \mathrm{df}, P=0 \cdot 006$ ).

Figure 2 shows the results of the multinomial logit model results for differences in label format, sodium level and hypertensive status. The corresponding numerical values are shown in Table 4. Consumers generally preferred the low-sodium product, and this effect was significantly stronger for people with hypertension than those without hypertension across all three label formats.

When no front-of-pack label was present, participants' ability to discriminate between the profiles was relatively weak, especially for the people without diagnosed hypertension. The introduction of a PDI label significantly increased the utility of the low-sodium product for both groups: from $2 \cdot 15(95 \% \mathrm{CI} 1 \cdot 97,2 \cdot 34)$ to $3 \cdot 31(95 \% \mathrm{CI}$ $3 \cdot 06,3 \cdot 59)$ for the people with hypertension and from 1.52 (95\% CI $1.31,1 \cdot 75)$ to $2 \cdot 49$ (95\% CI $2 \cdot 19,2 \cdot 83)$ for people without hypertension. However, the addition of the PDI label also increased the utility of the high-sodium product from 1.00 (reference category) for both groups to $1 \cdot 21(95 \%$ CI $1 \cdot 07,1 \cdot 36)$ for people with hypertension and 1.17 (95\% CI $0.98,1.39)$ for those without hypertension, although this was significant only for the group with hypertension. The TL label also sharply increased the utility of the low-sodium product compared with the NIP only control to $3 \cdot 39$ (95\% CI $3 \cdot 13,3 \cdot 68)$ for people with hypertension and $2 \cdot 57$ (95\% CI $2 \cdot 25,2 \cdot 93$ ) for those without diagnosed hypertension. However, the TL label

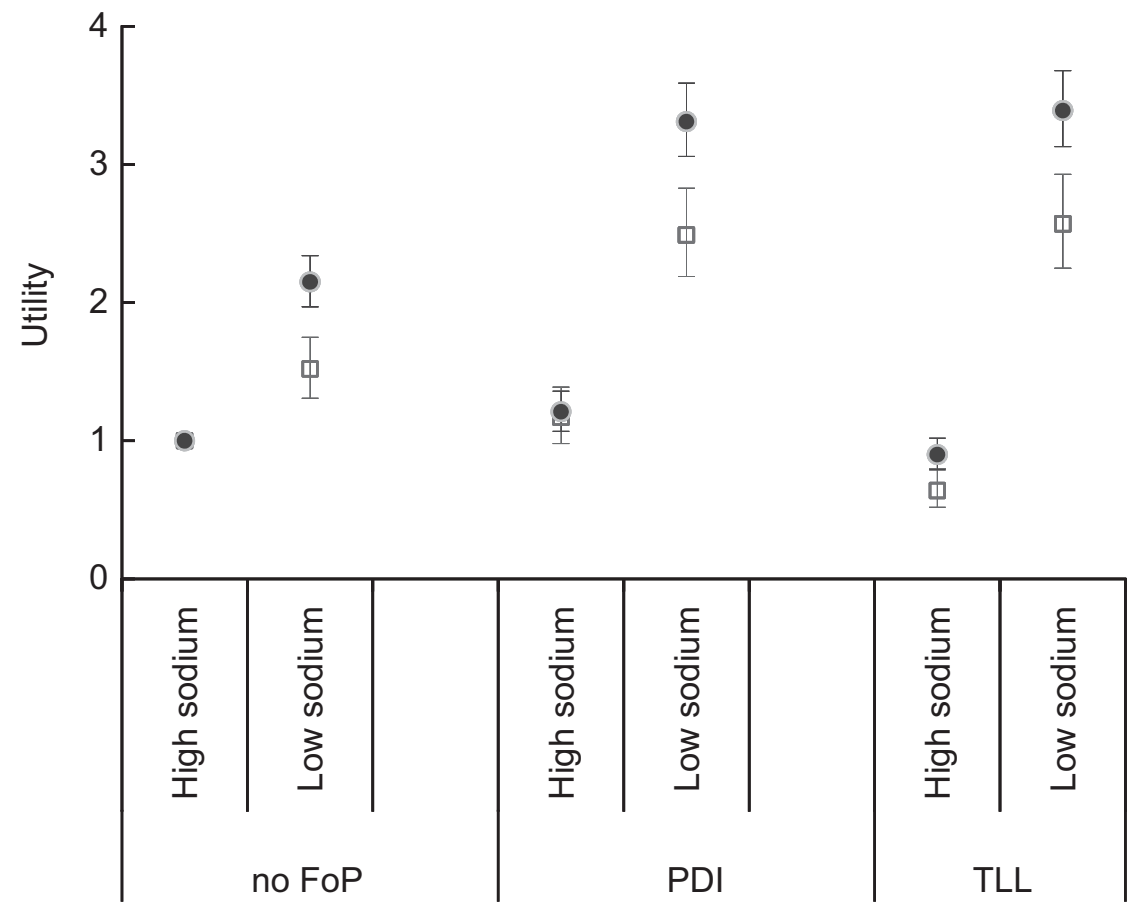

Fig. 2 Utility of different label formats (FoP, front-of-pack; PDI, Percentage Daily Intake; TL, Traffic Light) on choice behaviour for high- and low-sodium products, analysed by hypertensive status ( $\square$, not hypertensive, $n 191$; $\bullet$, hypertensive, $n 500$ ), among New Zealanders aged 18-79 years participating in an online nationwide research panel. Values are means, with $95 \%$ confidence intervals represented by vertical bars

Table 4 Multinomial logit regression results for utility based on different label formats by hypertensive status: New Zealanders aged 18-79 years participating in an online nationwide research panel

\begin{tabular}{|c|c|c|c|c|}
\hline \multirow[b]{2}{*}{ Label format } & \multicolumn{2}{|c|}{ Participants without diagnosed hypertension } & \multicolumn{2}{|c|}{ Participants with hypertension } \\
\hline & Utility & $95 \% \mathrm{Cl}$ & Utility & $95 \% \mathrm{Cl}$ \\
\hline High sodium, no FoP label & 1.00 & & $1 \cdot 00$ & \\
\hline High sodium, PDI label & $1 \cdot 17$ & $0.98,1.39$ & $1 \cdot 21^{\star *}$ & $1 \cdot 07,1 \cdot 36$ \\
\hline High sodium, TL label & $0.64^{\star *}$ & $0.52,0.80$ & 0.90 & $0.79,1.02$ \\
\hline Low sodium, no FoP label & $1 \cdot 52^{\star \star}$ & $1 \cdot 31,1 \cdot 75$ & $2 \cdot 15^{\star \star}$ & $1 \cdot 97,2 \cdot 34$ \\
\hline Low sodium, PDI label & $2 \cdot 49^{\star \star}$ & $2 \cdot 19,2 \cdot 83$ & $3 \cdot 31^{* *}$ & $3.06,3.59$ \\
\hline Low sodium, TL label & $2 \cdot 57^{\star \star}$ & $2 \cdot 25,2 \cdot 93$ & $3 \cdot 39^{\star \star}$ & $3.13,3.68$ \\
\hline
\end{tabular}

FoP, front-of-pack; PDI, Percentage Daily Intake; TL, Traffic Light.

Results are presented with two statistical significance levels: $P=0.05$ by convention and $P=0.01$ to account for multiple comparisons. Significantly different from 1.00 at ${ }^{*} P=0.05,{ }^{* \star} P=0.01$. 
reduced the utility of the high-sodium product to 0.90 (95\% CI $0.79,1.02)$ for people with hypertension and $0.64(95 \%$ CI $0.52,0.80)$ for people without diagnosed hypertension. Overall, the TL label resulted in the greatest discrimination between the profiles tested.

Figure 3 shows the results relating to our third hypothesis that 'reduced salt' or 'low salt' nutrition claims would interact with front-of-pack labels and reduce the influence these had on respondents' choice behaviour. We tested whether there was an interaction between hypertensive status and nutrition claim effect using the test of fixed effects. This showed that there was no significant interaction between hypertensive status and claim effect (Wald statistic $=0.54, P=0.765$ ) or any of the

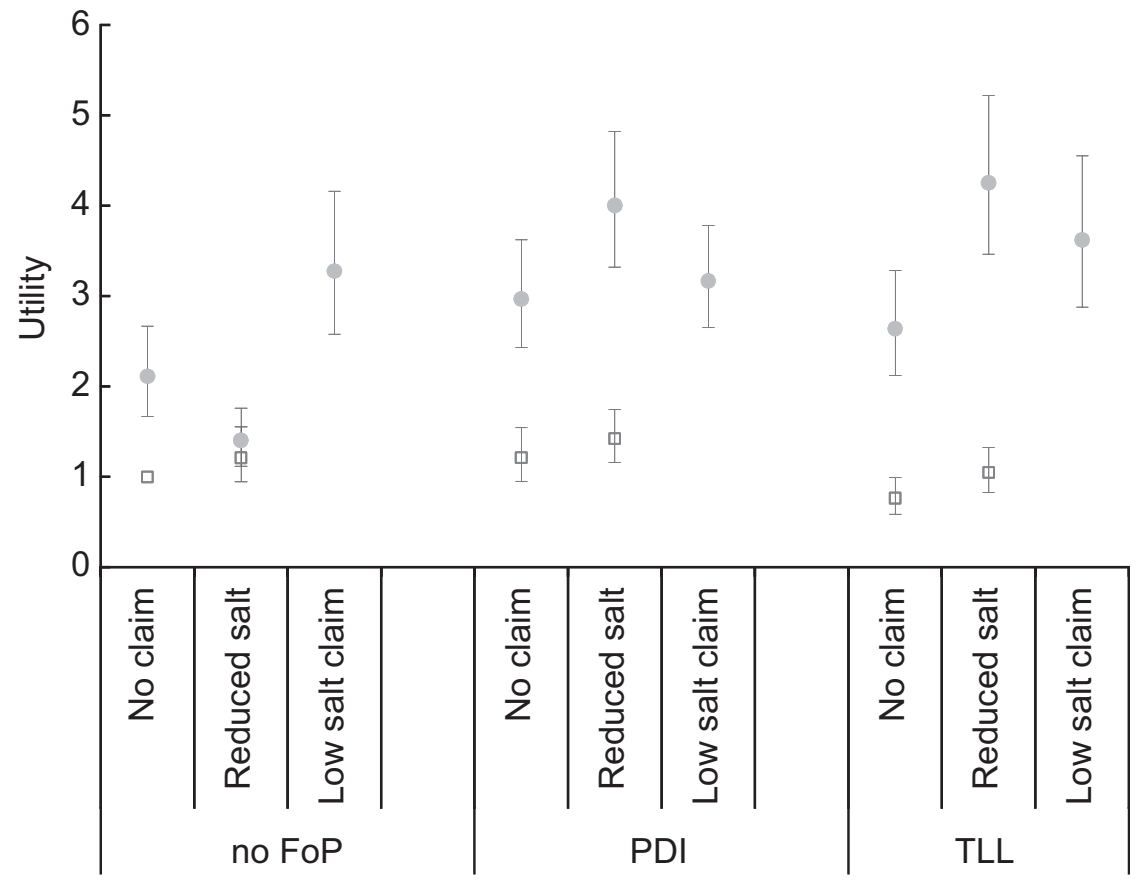

Fig. 3 Utility of different label formats (FoP, front-of-pack; PDI, Percentage Daily Intake; TL, Traffic Light) and nutrition claims ('reduced salt' and 'low salt') on choice behaviour for high-sodium $(\square)$ and low-sodium ( $)$ products among New Zealanders aged 18-79 years ( $n$ 691) participating in an online nationwide research panel. Values are means, with $95 \%$ confidence intervals represented by vertical bars

Table 5 Multinomial logit regression results for utility based on different label formats and presence of a nutrition claim for combined sample: New Zealanders aged 18-79 years participating in an online nationwide research panel

\begin{tabular}{lll}
\hline & \multicolumn{2}{c}{ Combined sample } \\
\cline { 2 - 3 } Label format & Utility & $95 \% \mathrm{Cl}$ \\
\hline High sodium, no FoP label (no claim) & $1 \cdot 00$ & $1 \cdot 67,2 \cdot 67$ \\
Low sodium, no FoP label (no claim) & $2 \cdot 11^{\star \star}$ & $0 \cdot 94,1 \cdot 55$ \\
High sodium, no FoP label (reduced salt claim) & $1 \cdot 21$ & $1 \cdot 12,1 \cdot 76$ \\
Low sodium, no FoP label (reduced salt claim) & $1 \cdot 40^{\star}$ & $2 \cdot 58,4 \cdot 16$ \\
Low sodium, no FoP label (low salt claim) & $3 \cdot 28^{\star \star}$ & \\
& & $0 \cdot 95,1 \cdot 54$ \\
High sodium, PDI label (no claim) & $1 \cdot 21$ & $2 \cdot 43,3 \cdot 62$ \\
Low sodium, PDI label (no claim) & $2 \cdot 97^{\star \star}$ & $1 \cdot 16,1 \cdot 74$ \\
High sodium, PDI label (reduced salt claim) & $1 \cdot 42^{\star \star}$ & $3 \cdot 32,4 \cdot 82$ \\
Low sodium, PDI label (reduced salt claim) & $4 \cdot 00^{\star \star}$ & $2 \cdot 65,3 \cdot 78$ \\
Low sodium, PDI label (low salt claim) & $3 \cdot 17^{\star \star}$ & $0 \cdot 59,1 \cdot 00$ \\
High sodium, TL label (no claim) & $0 \cdot 77$ & $2 \cdot 12,3 \cdot 29$ \\
Low sodium, TL label (no claim) & $2 \cdot 64^{\star \star}$ & $0 \cdot 83,1 \cdot 33$ \\
High sodium, TL label (reduced salt claim) & $1 \cdot 05$ & $3 \cdot 47,5 \cdot 22$ \\
Low sodium, TL label (reduced salt claim) & $4 \cdot 25^{\star \star}$ & $2 \cdot 88,4 \cdot 55$ \\
Low sodium, TL label (low salt claim) & $3 \cdot 62^{\star \star}$ &
\end{tabular}

FoP, front-of-pack; PDI, Percentage Daily Intake; TL, Traffic Light.

Results are presented with two statistical significance levels: $P=0.05$ by convention and $P=0.01$ to account for multiple comparisons.

Significantly different from 1.00 at ${ }^{\star} P=0.05,{ }^{\star \star} P=0.01$. 
interactions involving claim (Wald statistic $=0 \cdot 01$ to $0 \cdot 67$, $P=0.972$ to $0 \cdot 510$ ). As there was no significant difference between the two groups, we examined the effect of adding a nutrition claim on the combined (people with and without diagnosed hypertension) sample for simplicity, and to reduce multiple comparisons. The results are shown in Table 5.

In general, the addition of a nutrition claim was associated with an increased utility, especially in the presence of a front-of-pack label. For the low-sodium product, compared with the control no front-of-pack label, no claim product (utility $=2 \cdot 11,95 \%$ CI $1 \cdot 67,2 \cdot 67$ ), significantly higher utilities were seen in the PDI label 'reduced salt' claim (utility $=4 \cdot 00,95 \%$ CI $3 \cdot 32,4 \cdot 82$ ), the TL label 'reduced salt' claim (utility $=4 \cdot 25,95 \%$ CI $3 \cdot 47$, $5 \cdot 22$ ) and the TL label 'low salt' claim (utility $=3 \cdot 62$, 95 $\%$ CI $2 \cdot 88,4 \cdot 55)$ products. The exception to this general pattern was the no front-of-pack label 'reduced salt' claim product, which was not significantly different from the control no front-of-pack label, no claim product (utility $=1 \cdot 40,95 \%$ CI $1 \cdot 12,1 \cdot 76$ ).

For the high-sodium product (which was ineligible for the 'low salt' claim), the combination of a 'reduced salt' claim and a PDI label on the front of the pack was associated with a significantly increased utility of 1.42 (95\% CI 1.16, 1.74) compared with the control reference category of no front-of-pack label, no claim product (utility $=1 \cdot 00$ ), whereas the TL label 'reduced salt' claim product was not significantly different (utility $=1 \cdot 05$, $95 \%$ CI $0.83,1 \cdot 33$ ). For the high-sodium product the TL label was slightly (but significantly $P=0 \cdot 005$ ) less attractive than the PDI label.

\section{Discussion}

To our knowledge, the present research is first published that tests how alternative sodium nutrition label formats and nutrition claims influence consumers' choice behaviour. The results support the first hypothesis that consumers' ability to discriminate between foods with high and low sodium content increased as front-of-pack labels became less numeric and more visual. In this experiment the TL images facilitated healthier choices more effectively than either the PDI plus NIP or NIP alone formats. While both front-of-pack labels significantly increased consumers' ability to differentiate between high- and lowsodium products compared with the NIP alone, the TL label promoted greater discrimination and, in particular, enabled better identification of the high-sodium product.

The results also supported our second hypothesis; that consumers with hypertension would demonstrate stronger discrimination between high- and low-sodium foods when these featured nutrition labels that were less numeric and more visual. Figure 2 shows that those with hypertension were significantly more likely to choose low-sodium products than those without hypertension, and this effect was significantly higher with the addition of a front-of-pack label. There was also a greater difference between the utilities for high- and low-sodium products for people with hypertension and those without hypertension when a front-of-pack label was present. Interestingly, the PDI label increased the attractiveness (utility) of the high-sodium product for people with hypertension, whereas the TL label did not. The TL label significantly reduced the utility of the high-sodium product for people without hypertension. This result shows that the TL label more effectively enabled those with hypertension to avoid high-sodium processed foods. Although it is useful for consumers to easily recognize low-sodium products, calls for them to reduce sodium intake means they must be able to identify high-sodium products. It is particularly important that food labels designed to inform consumers about potentially harmful nutrients such as sodium do not in fact increase the attractiveness of products high in those nutrients, as the PDI label did in the present study.

Increasingly, researchers have concluded that simple visual labels such as the TL stimulate the greatest discrimination between products with differing nutrition profiles $^{(25,26)}$. Many people find nutritional information labels too time-consuming to read $^{(27)}$ and may lack both the mathematical ability to understand the information and the nutritional knowledge to interpret the information provided ${ }^{(21,28)}$. The rapid decision making that typically occurs in supermarkets may also preclude review of more detailed label formats ${ }^{(29)}$, with one observational study in the UK showing consumers spent an average of 29 s per product bought and $31 \cdot 8 \%$ of consumers were noted not to have looked at the product in detail ${ }^{(30)}$. This implies that many consumers find the time required to use nutrition information exceeds the time they have available to evaluate and compare food products ${ }^{(26,27)}$. The rapidity of consumers' decision making suggests they rely on habitual behaviours and heuristics, both of which simplify their choices, and raises the possibility that even knowledgeable consumers may not use nutrition labels if they feel under time pressure. Therefore simple labels that place fewer demands on consumers' numeracy and background knowledge such as the TL are more likely to promote healthful food choices. Our findings support this conclusion. In fact, in practice these differences may be greater in a supermarket setting, as although New Zealand consumers are familiar with the NIP and PDI, the TL is not currently in use. Once familiar with the TL format, New Zealand consumers may use it to even greater effect.

\section{Nutrition claims}

New Zealand allows nutrition claims such as 'reduced salt' and 'low salt', which consumers may use to identify lower-sodium products. However, nutrition claims may generate positivity bias, where consumers assume products 
featuring a nutrition claim are more healthful than is the case $\mathrm{e}^{(31)}$. In the present experiment, both the PDI and TL labels enabled better identification of the lowsodium product in the presence of a 'reduced salt' claim. For the high-sodium product only the TL label was able to counteract the potentially misleading effect of the 'reduced salt' claim.

Experience in Finland suggests that nutrition claims have the potential to reduce population salt intake ${ }^{(13)}$. However, from a public health perspective these claims are only useful if they are consistent with a product's nutrition profile. In this context current regulations permit a 'reduced salt' claim to be applied to a high-salt product if the food has at least $25 \%$ less sodium than a comparative reference food. This may be misleading if consumers believe that 'reduced salt claim' implies low sodium content. Our findings relating to nutrient content claims have particular salience since these claims may exert a stronger influence on consumers than the NIP, even when the claims made are inconsistent with the NIP. Food labelling regulations regarding sodium content need to ensure that foods are carefully screened before nutrition claims are permitted, as even in the presence of a PDI label a nutrition claim may actually enhance consumers' perceptions of a high-sodium product.

\section{Limitations}

There are several potential limitations to the present study. While the sample was not selected as nationally representative, the demographic profiles of participants broadly reflect the New Zealand population when compared with data from the most recent New Zealand Population Census of 2006 with respect to ethnicity and education $^{(32)}$. This leads us to believe that the results will be generalizable in the New Zealand context. The results are consistent with other international research ${ }^{(12,25)}$, and so are likely to have more general application. The online survey simulates behaviour in a supermarket, which is difficult to observe directly, and, while still removed from actual behaviour, it is closer to this than surveys eliciting self-reported estimates of behaviour. However, the results may have been affected by social desirability bias and so may not fully reflect actual purchasing behaviour, although the anonymity afforded by the online mode is likely to have reduced this potential error. In the experiment, only sodium content was varied; however, factors such as other nutrients or price may have a more powerful influence on actual purchasing behaviour and should be tested in future studies ${ }^{(33)}$. The role of more detailed label review at home in ongoing purchasing decisions should also be examined in future research.

\section{Conclusions}

Dietary sodium reduction is an important and costeffective public health strategy ${ }^{(7)}$. With 75 to $80 \%$ of dietary sodium intake coming from sodium contained in processed foods, reformulation is an important population wide strategy for dietary salt reduction. However, effective food labelling has the potential to enable consumers to moderate their own salt intake. The present results support the widespread use of front-of-pack labelling of sodium content and suggest a TL label, rather than a PDI label, would assist all consumers to discriminate between high- and low-sodium products more effectively. The TL label was particularly effective in enabling consumers to identify the high-sodium product, even in the presence of a nutrition claim. To avoid consumer deception, policy makers must ensure that nutrition claims are accurate, do not create misleading impressions about products' nutrition profiles, and are used together with an easily understood front-of-pack label such as a TL.

\section{Acknowledgements}

This study was funded by the Health Research Council of New Zealand through the University of Otago. There are no known conflicts of interests relating to this work. R.M. led the writing and contributed to the statistical analysis and design of the study. J.H. designed and supervised the study and contributed to the writing. D.H. led the statistical analysis and contributed to the writing. The authors are grateful to the Health Research Council of New Zealand for funding this study, and to Professor Jim Mann who provided helpful comments throughout.

\section{References}

1. World Health Organization (2006) Reducing Salt in Populations: Report of a WHO Forum and Technical meeting 5-7 October 2006, Paris, France. Geneva: WHO.

2. Australian Department of Health and Ageing, National Health and Medical Research Council \& New Zealand Ministry of Health (2006) Nutrient Reference Values for Australia and New Zealand. Canberra: Australian Department of Health and Ageing \& New Zealand Ministry of Health.

3. Stamler J, Rose G, Stamler R et al. (1989) INTERSALT study findings. Public health and medical care implications. Hypertension 14, 570-577.

4. Vollmer WM, Sacks FM, Ard J et al. (2001) Effects of diet and sodium intake on blood pressure: subgroup analysis of the DASH-Sodium Trial. Ann Intern Med 135, 1019-1028.

5. He FJ \& MacGregor GA (2009) A comprehensive review on salt and health and current experience of worldwide salt reduction programmes. J Hum Hypertens 23, 363-384.

6. He FJ \& MacGregor GA (2010) Reducing population salt intake worldwide: from evidence to implementation. Prog Cardiovas Dis 52, 363-382.

7. Bibbins-Domingo K, Chertow GM, Coxson PG et al. (2010) Projected effect of dietary salt reductions on future cardiovascular disease. $N$ Engl J Med 362, 590-599.

8. Mattes RD \& Donnelly D (1991) Relative contributions of dietary sodium sources. J Am Coll Nutr 10, 383-393.

9. James WPT, Ralph A \& Sanchez-Castillo CP (1987) The dominance of salt in manufactured food in the sodium intake of affluent societies. Lancet 1, 426-429. 
10. Medical Research Council Human Nutrition Research (2005) Why 6 g? A Summary of the Scientific Evidence for the Salt Intake Target. Cambridge: Medical Research Council.

11. Wyness LA, Butriss JL \& Stanner SA (2012) Reducing the population's sodium intake: the UK Food Standards Agency's salt reduction programme. Public Health Nutr 15, 254-261.

12. Campos S, Doxey J \& Hammond D (2011) Nutrition labels on pre-packaged foods: a systematic review. Public Health Nutr 14, 1496-1506.

13. Pietinen P, Valsta LM, Hirvonen T et al. (2008) Labelling the salt content in foods: a useful tool in reducing sodium intake in Finland. Public Health Nutr 11, 335-340.

14. Malam S, Clegg S, Kirwan S et al. (2009) Comprehension and Use of UK Nutrition Signpost Labelling Schemes. London: British Market Research Bureau Social Research.

15. Institute of Medicine (2010) Examination of Front-ofPackage Nutrition Rating Systems and Symbols: Phase I Report. Washington, DC: The National Academies Press.

16. EurActiv.com (2010) Food industry wins battle on 'traffic light' labels. http://www.euractiv.com/en/food-industrywins-battle-traffic-light-labels-news-495324 (accessed July 2011).

17. Gilbey A \& Fifield S (2006) Nutritional information about sodium: is it worth its salt? $N Z$ Med J 119, U1934.

18. Grimes CA, Riddell LJ \& Nowson CA (2009) Consumer knowledge and attitudes to salt intake and labelled salt information. Appetite 53, 189-194.

19. New Zealand Food and Grocery Council (2010) The Daily Intake Guide. Wellington: New Zealand Food and Grocery Council; available at http://www.fgc.org.nz/daily_ intake.asp

20. Tanner RJ \& Carlson KA (2009) Unrealistically optimistic consumers: a selective hypothesis testing account for optimism in predictions of future behaviour. $J$ Consum Res 35, 810-822.

21. Ni Mhurchu C \& Gorton D (2007) Nutrition labels and claims in New Zealand and Australia: a review of use and understanding. Aust N Z J Public Health 31, 105-112.
22. Food Standards Australia \& New Zealand (2010) Standard 2.10.2 - Salt and Salt Products. http://www.foodstandards. gov.au/foodstandards/foodstandardscode/standard2102 saltands4286.cfm (accessed March 2010).

23. Macfie HJ \& Bratchell N (1989) Designs to balance the effect of order of presentation and first-order carry-over effects in hall tests. J Sens Stud 4, 129-148.

24. Chen Z \& Kuo L (2001) A note on the estimation of the multinomial logit model with random effects. Am Stat $\mathbf{5 5}$, 89-95.

25. Cowburn G \& Stockley L (2005) Consumer understanding and use of nutrition labelling: a systematic review. Public Health Nutr 8, 21-28.

26. Grunert K \& Wills J (2007) A review of European research on consumer response to nutrition information on food labels. J Public Health 15, 385-399.

27. Signal L, Lanumata T, Robinson J et al. (2008) Perceptions of New Zealand nutrition labels by Maori, Pacific and lowincome shoppers. Public Health Nutr 11, 706-713.

28. Rothman R, Housam R, Weiss H et al. (2006) Patient understanding of food labels: the role of literacy and numeracy. Am J Prev Med 31, 391-398.

29. Hutchinson JW \& Alba J (1991) Ignoring irrelevant information: situational determinants of consumer learning. J Consum Res 18, 325-345.

30. Grunert K, Wills J \& Fernandez-Celemín L (2010) Nutrition knowledge, and use and understanding of nutrition information on food labels among consumers in the UK. Appetite 55, 177-189.

31. Roe B, Levy AS \& Derby BM (1999) The impact of health claims on consumer search and product evaluation outcomes: results from FDA experimental data. J Public Policy Mark 18, 89-105.

32. Statistics New Zealand (2006) 2006 Census. Wellington: Statistics New Zealand; available at http://www.stats. govt.nz/Census/2006CensusHomePage.aspx

33. Andreyeva T, Long MW \& Brownell KD (2010) The impact of food prices on consumption: a systematic review of research on the price elasticity of demand for food. $A m J$ Public Health 100, 216-222. 